\title{
If I only had a heart: The trials and tribulations of ventricular assist device support when missing a ventricle
}

\author{
Chet R. Villa, MD, and David L. S. Morales, MD
}

From The Heart Institute, Cincinnati Children's Hospital Medical Center, Cincinnati, Ohio.

Disclosures: Dr Morales is a consultant for Berlin Heart, Medtronic, Abbot, and Syncardia. Dr Villa has nothing to disclose with regard to commercial support.

Received for publication April 1, 2018; accepted for publication April 6, 2018; available ahead of print May 8, 2018.

Address for reprints: David L. S. Morales, MD, The Heart Institute at Cincinnati Children's Hospital Medical Center, 3333 Burnet Ave, MLC 2004, Cincinnati, OH 45229 (E-mail: David.Morales@ cchmc.org).

J Thorac Cardiovasc Surg 2018;156:746-7

$0022-5223 / \$ 36.00$

Copyright $(2) 2018$ by The American Association for Thoracic Surgery

https://doi.org/10.1016/j.jtcvs.2018.04.013

Drs Kato and Gandhi ${ }^{1}$ have nicely described an innovative support strategy to a challenging patient population, something the senior author has done for our field in the past. The field has yet to define the optimal approach to support infants, especially those requiring biventricular support. The authors have provided a useful and detailed roadmap for creating a "total artificial heart" in infants requiring biventricular support, by using 2 Berlin Heart EXCORs (Berlin Heart GmbH, Berlin, Germany) and performing a cardiectomy.

A combination of cardiectomy and biventricular support has been reported previously in larger patients with singleventricle physiology, with mixed results. ${ }^{2,3}$ The theoretical benefit gained by cardiectomy must be balanced by the limited compliance of the atria and Berlin EXCOR. In previous case reports, elevated central and pulmonary venous pressures were a significant problem. . $^{2,3}$ The persistent chylous effusion and early, significant renal dysfunction described in the current report suggest that this might be a consistent problem. However, this problem can be managed well. The key may in fact be in the author's title. The "total artificial heart" described by the authors does mimic the Syncardia Total Artificial Heart (SynCardia Systems, LLC, Tucson, Ariz) in many ways and thus patient management might need to be similar. The Syncardia Total Artificial Heart is able to provide a supranormal cardiac output in the setting of low central venous pressure despite cardiectomy by running the pumps fast, to achieve "partial fill and full eject." This management strategy might accommodate for the inherent lack of compliance of the anatomy/support device. Other groups have attempted to address the issue of venous hypertension through the use of paracorporeal, continuous flow devices. ${ }^{3}$ Whichever approach is taken, centers should be acutely aware of the issue and take appropriate monitoring and management steps. Without a decrease in central and pulmonary venous pressures, the benefits of ventricular assist device (VAD) support (end organ recovery and rehabilitation)

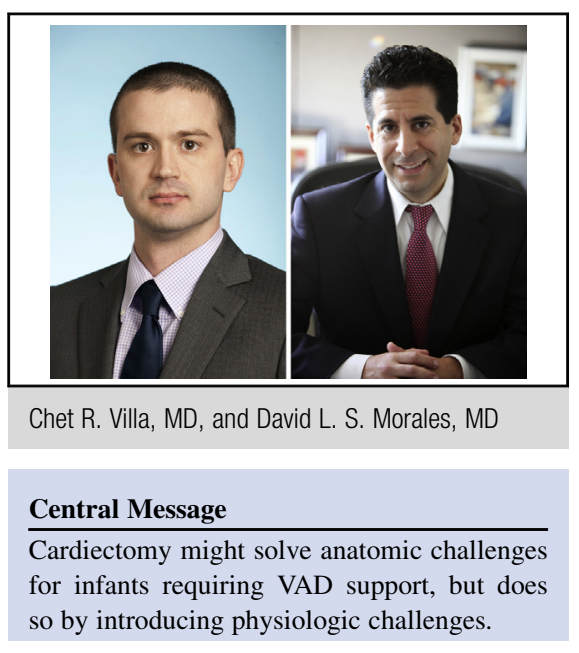

See Article page 743.

will be limited and there will be significant risk of adverse outcomes before as well as after transplantation.

Infants, especially those with single-ventricle physiology, are a significant challenge to manage and support with standard implantation of the EXCOR. ${ }^{4-7}$ This has led centers to consider novel cannulation and patient management strategies. A recent study from the Pediatric Interagency Registry for Mechanical Circulatory Support as well as discussions in the pediatric VAD community via Advanced Cardiac Therapies Improving Outcomes Network suggests that paracorporeal, continuous flow devices with atrial cannulation appears to be the growing trend for supporting single-ventricle physiology because of its increasingly consistent success. Many believe that the ability to accommodate for the significant VAD preload/volume load due to via a shunt or aorto-pulmonary collaterals is what has been leading to improved outcomes for this population. ${ }^{8}$ However, the authors present another potential solution for this issue in single-ventricle patients, which is creating a 2 -ventricle physiology. The optimal approach remains unclear. The answer cannot come soon enough because the outcomes for infants, especially those with single-ventricle physiology, trail the outcomes for older patients and those with 2-ventricle congenital heart disease. $^{9}$

\section{References}

1. Kato H, Gandhi SK. Use of Berlin Heart ventricular assist devices as a total Q1 artificial heart. J Thorac Cardiovasc Surg. 2018;156:743-5. 
2. Valeske K, Yerebakan C, Mueller M, Akintuerk H. Urgent implantation of the Berlin Heart Excor biventricular assist device as a total artificial heart in a patient with single ventricle circulation. J Thorac Cardiovasc Surg. 2014; 147:1712-4.

3. VanderPluym CJ, Khoo NS, Rebeyka IM, Buchholz H. Unique case of total artificial cardiac support in failed Fontan circulation after cardiectomy: is continuous flow better than pulsatile flow? J Thorac Cardiovasc Surg. 2013; $145: \mathrm{e} 62-3$.

4. Almond CS, Morales DL, Blackstone EH, Turrentine MW, Imamura M, Massicotte MP, et al. Berlin Heart EXCOR pediatric ventricular assist device for bridge to heart transplantation in US children. Circulation. 2013;127:1702-11.

5. Weinstein S, Bello R, Pizarro C, Fynn-Thompson F, Kirklin J, Guleserian K, et al. The use of the Berlin Heart EXCOR in patients with functional single ventricle. J Thorac Cardiovasc Surg. 2014;147:697-704; discussion 704-5.
6. Conway J, St Louis J, Morales DL, Law S, Tjossem C, Humpl T. Delineating survival outcomes in children $<10 \mathrm{~kg}$ bridged to transplant or recovery with the Berlin Heart EXCOR ventricular assist device. JACC Heart Fail. 2015;3:70-7.

7. Morales DLS, Zafar F, Almond CS, Canter C, Fynn-Thompson F, Conway J, et al Berlin Heart EXCOR use in patients with congenital heart disease. J Heart Lung Transplant. 2017;36:1209-16.

8. Lorts A, Eghtesady P, Mehegan M, Adachi I, Villa C, Davies R, et al. Outcomes of children supported with devices labeled as "temporary" or short term: a report from the pediatric interagency registry for mechanical circulatory support. J Heart Lung Transplant. 2018;37:54-60.

9. Blume ED, VanderPluym C, Lorts A, Baldwin JT, Rossano JW, Morales DLS, et al. Second annual pediatric interagency registry for mechanical circulatory support (PediMACS) report: pre-implant characteristics and outcomes. J Heart Lung Transplant. 2018;37:38-45. 